\title{
THE INTERVIEW AS A QUALITATIVE RESEARCH INSTRUMENT
}

\author{
Ştefan-Dominic GEORGESCU ${ }^{a^{*}}$, Ionuț-Emilian ANASTASIU ${ }^{b}$ \\ ${ }^{a, b}$ Bucharest University of Economic Studies, Romania
}

\begin{abstract}
The paper describes the interview as an essential instrument in the social field research. Therefore, the main purpose of the interview is to obtain certain information about one or more research issues. Sociological theorists have argued that there are three fundamental types of interview: the standardized (formal or structured) interview, the un-standardized (informal or non-directive) interview, and the semi-standardized (guided-semi-structured or focused) interview. The semistandardized interview has a pronounced qualitative side, its area of use being extremely varied, in this sense including both the field of human resources - the employment interview, the performance measurement interview, etc. - as well as that of sociology, anthropology, ethnology or psychology.
\end{abstract}

KEYWORDS: qualitative research, non-directive interview, semi-standardized interview, standardized interview.

DOI: $10.24818 / \mathrm{IMC} / 2021 / 05.14$

\section{INTRODUCTION}

The interview is usually understood as a modality to have a conversation that aims to achieve certain goals. During the interview, the interviewer asks a series of questions to pre-selected people, from which expects to obtain intelligible answers. The interview is therefore used both in the daily life of people, as well as various fields of knowledge such as sociological field research, journalism, or human resources, etc. The interview as a way of gathering information has come to be practiced with such frequency that Atkinson and Silverman (1997), in a study about Milan Kundera's novel Immortality, claim that people live in an "interview society".

In this regard, social science researchers argued that the main purpose of the interview is to obtain certain information about one or more research issues. Furthermore, it can be seen that there is a high degree of agreement of these specialists regarding the definition of the interview as a research tool. This does not mean that social sciences researchers have shown a consensus on how to conduct, to put the interview into practice. All the more so as we can see that, in recent years, a very extensive literature has been published on the ways in which the interview can be conducted as a research tool.

\section{THE STANDARDIZED INTERVIEW}

As can be seen, there is a vast literature in the field, which includes, on the one hand, numerous works with a rather minimal content and a guiding role, which is limited to offering a series of tips and suggestions on what should be done in an interview and what should not be done in any way, or should be avoided in the interview. On the other hand, there are numerous works that contain analyzes at a very high theoretical level on the notions of intuition, communication, empathy, etc. In this case, it insists on the cognitive dimension of this research instrument, as well as the relationships between the interview and other research tools both qualitative and quantitative.

\footnotetext{
${ }^{*}$ Corresponding author. E-mail address: dominic.stefan@man.ase.ro
} 
There is also an approach who understands the interview as an art rather than part of a scientific approach; in this sense, conducting an interview is more about a person's inner abilities and resources than a person's ability to learn certain techniques and basic rules needed to conduct the interview. In this case, therefore, the interview can only be conducted by some people, whose creativity, imagination and artistic talent are highly developed, while others find it almost impossible to conduct an interview in a relevant and convincing way. It should be emphasized from now on that the authors of this study consider such a super elitist conception of the interview to be profoundly erroneous, a conception that ignores the fact that people are capable of change and lifelong learning. The authors' belief is that, insofar as they show a minimum of availability and empathy, and have a range of basic knowledge, any person can conduct an interview that brings to light information with a high degree of relevance. In this sense, in the opinion of the authors, the interview represents one of the most recommended research tools for the realization of the bachelor's thesis, the dissertation, as well as the doctoral thesis in social sciences.

In order to be able to conduct a field research in which the interview is the research instrument, it should be noted that there are several types of interview. The classification of interviews has been a key concern for countless researchers, but we will keep in mind for the moment the existence of three essential categories of interviews (Berg 2001): the standardized (formal or structured) interview, the un-standardized (informal or non-directive) interview, and the semi-standardized (guided-semistructured or focused) interview. We will make them explicit in order.

The standardized or structured interview has as an essential feature the fact that it is based on a fixed structure of questions, which cannot be changed from one respondent to another during the field research. In this way, all respondents, without exception, will provide answers to the same questions, so that comparisons can be made with a high degree of accuracy between the answers provided by respondents. This research tool was initially used in a relatively vast way during the Second World War, and this because it allowed the achievement of extensive and systematic studies on a very large number of soldiers without incurring exorbitantly high costs. Also, the statistical analysis and interpretation of the data could be done in a very short time.

The structured interview cannot be conducted in the absence of research objectives very rigorously fixed; it also always starts from the premise that the questions from the interview guide have a high degree of comprehension so that it not only can be understood by all respondents in an identical way, but also provide relevant information for field research. In other words, the structured interview aims to extract information based on predetermined sets of questions whose objective is to highlight the beliefs, points of view, opinions, as well as the expectations and attitudes of the respondents regarding the researched issue.

The fundamental elements that make up the standardized interview are the following: the use of a unique set of questions that do not change from one respondent to another, categories of predetermined answers based on closed-ended questions, strict control of the conditions in which the interview takes place by using a work plan set out in the smallest details. Also, all interviewees should be treated in the same way, the researcher being not allowed to influence their opinions in any way. Only in this way can the data obtained on the basis of the structured interview be used properly and the differences between the opinions of the respondents can be compared with each other; On the other hand, these differences of opinion should not be generated by the conversation with the person who conducted the interviews, but should be based on sociological indicators such as gender, age, profession, urban or rural background, etc.

In addition, sociologists have established that there is a set of rules that must be followed in order to conduct standardized interviews (adapted from Marvasti, 2004):

1. The researcher must read the questions exactly in the form in which they are written. Also, the order in which respondents are asked to answer the questions from the interview guide should always be the same, without exception. 
2. If an interviewee does not provide a complete answer to one of the questions included in the interview guide, then the researcher must address to him or her one or more of the standard informal formulas, whose role is to help the subject provide a better answer. These standard formulas can be the following: repeating the question for a better understanding of it, including a phrase such as "Please tell me more about ...", or asking additional questions like "Anything else?" or "What do you mean by that?". These formulations have the role of unblocking the communication and overcoming the various blockages that may occur during the interview, as well as to bring a higher clarification of the interviewee's perceptions on the object of the research.

3. During the interview, a relaxed atmosphere must be maintained, without giving to the subjects the impression that other objectives besides those officially communicated are targeted, and they must ensure that their personal data are protected.

4. The answers of the subjects during the research must be recorded without interpreting them. In the situation where a certain question is open-ended, requiring the interviewee to provide his or her own, non-standardized, answer, which is not included in a list of answers as in the case of the questionnaire, then it is mandatory to record the answers given the interviewee to the question.

5. It is recommended that, at all times, a neutral, professional-type relationship be maintained between the interviewer and the interviewees. The researcher should not provide information about his or her private life or family, nor should he or she express his or her views for or against a particular event, social actor, political figure, or various governmental strategies regarding the topic in question. In addition, it is necessary for the researcher to avoid providing feedback to the subjects regarding the opinions expressed by them in the interview.

Under these rules, social sciences researchers consider that the main sources from which the error can come are, on the one hand, the faulty use of the data collection method and, on the other hand, the lack of experience and training in the field of data collection of the person conducting the interviews.

The standardized interview has some advantages, which can be summarized as follows (adapted from Howitt \& Cramer, 2011):

- a large number of interviews can be conducted in a relatively short time; in fact, it is the fastest way to collect data through the interview, and it is always advisable to use the standardized interview when there is a lot of time pressure to quickly obtain certain relevant data.

- while, in the case of the questionnaire, there may be situations in which some samples of persons provide a very low response rate, which directly leads to a decrease in the sample, this situation can be eliminated due to the fact that the participants can be recruited on the spot, therefore the response rate can be maintained in a satisfactory percentage.

- allows a fast computerized analysis of the data, being, to some extent, the only type of interview that allows such an analysis regarding the totality of the data.

- the research can be carried out in a very fast time, which implies the fact that, most of the times, the clients or beneficiaries of the field researches can have fast access to the information, respectively to the research reports. This emphasis on the speed with which data are obtained is often a major obstacle to conducting qualitative research, which involves a much longer lead time, and the stereotype that a large sample invariably provides a much more accurate picture of reality than a small sample, made up of the interviewees from a qualitative research.

As a result, since the beginning of the predominantly quantitative field research, a distinction has been made between the planning specific to the sociological survey administered by the researcher, or, in other words, the survey in which the researcher asks the same questions to all subjects, on the one hand, and the questionnaire that forms part of the self-administered sociological survey, in which the subject completes the questionnaire without being assisted by a sociologist. However, the situation in which the respondent does not offer the answers that derive from his beliefs and opinions should not be ignored, but the ones he thinks the interviewer wants to hear about. Such a phenomenon has been described in the literature through the concept called the effect of social desirability. This is defined as 
the tendency of field research subjects to distort their own opinions, beliefs, and feelings by answering the researcher's questions in a manner considered socially acceptable (Marvasti, 2004). For example, a field research on domestic violence in Romania highlights the fact that the vast majority of male respondents state that they either never assaulted their wife or did so at very long intervals, and that the assaults were always minor, or only verbal. The social reality is, however, radically different: domestic violence has an extremely high level in Romania, but, due to the fact that domestic violence is socially disavowed, the research subjects offer cosmetic answers. In this situation, it is advisable to replace the question "At what time frame do you assault your life partner?" with the question "At what time frame do the episodes of anger manifest towards the life partner?".

\section{THE NON-DIRECTIVE INTERVIEW}

Unlike the standardized interview, which is characterized by the inflexible pursuit of a plan established prior to the field research itself, as well as an interview guide in relation to which no deviation is allowed, the non-directive interview offers both the researcher and the research subjects an infinitely higher degree of freedom.

In this case, the presupposition from which the researcher starts is that the social universe to be researched has a high degree of novelty, so that the careful elaboration of an interview guide would have the consequence of distorting the research results, limiting or even canceling some original information, the collection of which can only be done in a given research universe. The use of this type of interview is recommended in situations where the linguistic level of the people to be interviewed is very different, their vocabulary presenting specific elements, such as regionalisms or the frequent use of technical or artistic terms to which only specialists in a certain field have access. It is also recommended to use this type of interview when the interviewees are personalities from a certain cultural-artistic or technical field.

In fact, one of the common situations in research where the un-standardized interview is used is that in which the researcher tries to adapt a set of questions to a certain social universe, who is made up of heterogeneous elements and which presents a great complexity in terms of how to perceive a certain social issue. The non-directive interview can be used in field research when it is concluded that some of the research subjects do not give the same meaning to the concepts or notions used in the interview guide, which was elaborated well before the actual research. In such a situation, it is therefore necessary to abandon almost all the previously elaborated questions and to spontaneously formulate new questions, which allow each interviewee to answer in a way that is as comprehensible as possible, the answers provided being a faithful replica of the interviewee's perception of the object under investigation.

As a direct consequence of its very nature, the informal interview derives directly not from the interview preparation stage, but from the interaction that is established between the interviewer and the interview subjects, which implies a deep implication of the researcher in fieldwork. Therefore, qualitative field research conducted on the basis of the non-directive interview bears the direct imprint of the researcher and may have as its general objective the verification of research questions that are provided by research undertaken on the basis of field observation.

\section{THE SEMI-STANDARDIZED INTERVIEW}

In qualitative research, the semi-standardized interview, on the other hand, is referred to as an indepth interview. As its name suggests, the semi-structured interview consists of a number of predetermined questions, as well as one or more predetermined topics. The predetermined questions are addressed to all the interviewed persons of which the sample is composed, respecting the same order and their arrangement in the interview guide. However, apart from these predetermined questions, the semi-structured interview allows the interviewees to develop certain topics of discussion, but also to propose new topics of conversation. 
To describe the focused interview, Kvale (1996) uses two distinct metaphors, very suggestive in fact: the miner metaphor and the traveler metaphor. Thus, on the one hand, "knowledge is understood as buried metal and the interviewer is a miner who unearths the valuable metal", and, on the other hand, the interviewer as a traveler "asks questions that lead the subjects to tell their own stories of their lived world, and converses with them in the original Latin meaning of conversation as 'wandering together with"'. One of the major differences between the standardized and the semi-standardized interview is in the language adopted; While the standardized interview uses language that is understandable to all respondents, the semi-structured interview involves asking personalized questions that can only be asked of a specific person or small group. In general, qualitative research is concerned with highlighting the distinctive elements, namely what differentiates a group of people or a community in relation to the vast majority of people.

The semi-standardized interview involves giving a special interest to the universe of the interviewees. In fact, one of the essential rules for conducting the semi-standardized interview is not to be confused with a simple conversation, in the sense that the interviewees can and should be stimulated to talk about themselves, while the interviewer will do so only very rarely, in situations where this is somewhat inevitable and involves the establishment of an atmosphere of trust between the researchers and the interviewee.

The topics addressed in the in-depth interview are dynamic, being able to be initiated and developed not only by the researcher, but also, to a lesser extent, by the interviewees. In addition, the investigation has a strong exploratory character and is oriented in collecting the data in a more detailed way. While the standardized interview has an inflexible structure, it is invariably based on an interview guide consisting of well-articulated questions, which require answers that can be quantified mathematically, the in-depth interview has a flexible character, the specific interview guide being permanently open to various changes from one respondent to another, as well as a weak standardization.

The main features of the semi-standardized interview are the following (adapted from Ritchie \& Lewis, 2003):

- it tends to combine structure with flexibility, but with an emphasis on flexibility.

- it has an interactive dimension, based fundamentally on the interaction between the interviewer and the interviewee, which takes place face to face.

- the in-depth interview also has an exploratory character, the researcher being interested in revealing the beliefs, opinions, motivations and, why not, the feelings of the interviewees;

- it is a creative instrument, both the interviewer and the interviewee having the freedom to open previously unexplored research directions;

- it is difficult and not recommended that the semi-standardized interview be conducted in the laboratory, but in the natural environment of the interviewee. In this regard, it is recommended that the interview be recorded, in order to preserve the statements of the interviewee in an authentic form, which cannot be done when the interviewer takes notes.

\section{REFERENCES}

Atkinson, P. \& Silverman, D. (1997). Kundera's Immortality: The Interview Society and the Invention of the Self. Qualitative Inquiry, 3(3), 304-325.

Berg, B. L. (2001). Qualitative research methods for the social sciences. Needham: Allyn and Bacon.

Howitt, D. \& Cramer, D. (2011). Introduction to research methods in psychology. Harlow: Pearson.

Kvale, S. (1996). Interviews: An Introduction to Qualitative Research Interviewing. Thousand Oaks: SAGE Publications.

Marvasti, A. B. (2004). Qualitative Research in Sociology. London: SAGE Publications.

Ritchie, J. \& Lewis, J. (eds.) (2003). Qualitative Research Practice: A Guide for Social Science Students and Researchers. London: SAGE Publications. 